\title{
EDUCAÇÃO COMPARADA: DESAFIOS E POSSIBILIDADES NO CAMPO METODOLÓGICO
}

\author{
EDUCACIÓN COMPARATIVA: RETOS Y POSIBILIDADES EN EL ÁMBITO \\ METODOLÓGICO
}

\section{COMPARATIVE EDUCATION: CHALLENGES AND POSSIBILITIES IN THE METHODOLOGICAL FIELD}

Rosimeire dos SANTOS ${ }^{1}$ Luciana Siqueira Rosseto SALOTTI ${ }^{2}$

A Revista On line de Política e Gestão Educacional, em seu número especial XX de novembro de 2021, apresenta um compilado de estudos de pesquisadores ligados ao Grupo de Pesquisa - Coletivo de Professores e Pesquisadores em Políticas Públicas (COPPE) da Pós-graduação em Educação da Universidade Estadual Paulista - campus de Marília, bem como estudos de autores convidados que desenvolvem pesquisas na área educacional.

O COPPE vem, desde 2009, dedicando-se aos estudos voltados para a Educação Comparada e Internacional, seus desafios, possibilidades e contribuições. Em relação aos estudos comparativos em Educação, em termos de Brasil, observa-se que a maioria dos cursos de formação de professores não contempla a Educação Comparada em suas trajetórias formativas, mesmo não se constituindo um campo recente e contando com um acervo considerável de defensores.

Autores como: Franco (2000), Cook, Hite e Epstein (2004), Ferreira (2009), Nóvoa (2009), Mitter (2012) e Carvalho (2014) apresentam um panorama da Educação Comparada, desde Marc-Antonie Julien (1817), seu percurso, até autores contemporâneos, que mesmo ao tecer críticas aos estudos comparativos, valorizam esses estudos e assinalam sua importância.

${ }^{1}$ Universidade Estadual Paulista (UNESP), Araraquara - SP - Brasil. Membro do Grupo de Pesquisa COPPE e do Grupo de Pesquisa Rede Internacional de Investigação em Altas Capacidades - REINEVA. Assessora Técnica da Secretaria Municipal da Educação de Assis. Doutorado em Educação Escolar (FCLAR). ORCID: https://orcid.org/0000-0003-1169-5322. E-mail: assessoriatecnicasme@gmail.com

2 Faculdade de Tecnologia de Assis "Prof. Dr. José Luiz Guimarães" (FATEC), Assis - SP - Brasil. Professora Doutora da FATEC - Assis. Membro do Grupo de Pesquisa COPPE. Doutorado em Linguística Aplicada aos Estudos da Linguagem (PUC). ORCID: https://orcid.org/0000-0002-5432-2553. E-mail: lucianasrsalotti@gmail.com

RPGE- Revista on line de Política e Gestão Educacional, Araraquara, v. 25, n. esp. 4, p. 1874-1880, dez. 2021. e-ISSN: 1519-9029 DOI: https://doi.org/10.22633/rpge.v25iesp.4.15929 
A construção das primeiras obras de caráter científico em estudos comparativos tem seu ponto de partida no final do século XIX, período no qual ocorreu o processo de criação dos sistemas de ensino, base da construção dos estudos comparativos em educação, que tem por objeto de estudo os sistemas nacionais de educação.

No entanto, Cook, Hite e Epstein (2004), assinalam que a comparação entre sistemas de ensino não é atualmente o tópico mais discutido na Educação Comparada. Com o advento da globalização, esses autores consideram seus reflexos como uma temática a ser explorada.

Os questionamentos sobre os processos de globalização, que influenciam significativamente as decisões políticas, tanto em relação à sua estrutura quanto à organização dos sistemas de ensino, podem extrapolar as fronteiras nacionais, abordar as questões da modernidade e da tecnologia, compreender e valorizar os aspectos culturais, econômicos, históricos e sociais daquele ou daqueles países.

Dessa forma, consideramos que a metodologia dos estudos comparativos na área da Educação, vem, em grande medida, retomando sua importância em termos acadêmicos. Exatamente por estarmos diante dessa situação, essa publicação poderá contribuir para o aprofundamento dos estudos e pesquisas com esse enfoque.

O primeiro artigo deste número, intitulado Panorama Histórico da Educação Comparada - as contribuições de George Bereday, apresenta um ângulo do panorama histórico traçado pela Educação Comparada. Segundo a revisão bibliográfica documental realizada, assinalando as diferentes divisões em fases ou períodos propostos pelos autores clássicos e mais especificamente apresenta a proposta do método comparativo de Bereday (1972).

Considerando a importância de contemplar nos currículos de formação de professores e suscitar essa discussão, o artigo Educação Comparada: apontamentos sob a ótica de estudantes da Pós-Graduação em Educação faz uma análise da Educação Comparada a partir do material básico apresentado na disciplina "Introdução aos Estudos de Educação Comparada e Internacional”, do Programa de Pós-Graduação em Educação da UNESP, campus de Marília/SP, voltado principalmente para a investigação e os procedimentos metodológicos. Os autores destacam que a análise do material explorado no desenvolvimento da disciplina permite inferir que os estudos voltados nessa perspectiva não buscam tão somente encontrar semelhanças ou diferenças, mas promover discussões aprofundadas acerca do papel da Educação Comparada para o desenvolvimento educacional e sua influência na história da educação, permeando desafios, possibilidades e contribuições. 
Para se compreender a trajetória da Educação Comparada e com a finalidade de delinear o método de pesquisa em Educação Comparada proposto por George Bereday e explicitar algumas opiniões sobre o mesmo, os autores do artigo A Proposta Metodológica de Bereday para a Educação Comparada: comentários e possibilidades partindo das considerações de renomados autores como: Bonitatibus (1989), Bray e Thomaz (1995), Lourenço Filho (2004) e Nóvoa (2010) buscam trazer luz ao entendimento do que é a Educação Comparada e como realizar pesquisas e estudos comparativos na área da educação.

Em Políticas Públicas Educacionais e Democracia no cenário Político Brasileiro, os autores analisam a relação, nem sempre explícita, entre políticas públicas educacionais e democracia, a fim de repercutir a compreensão dessas correlações na educação contemporânea e na consolidação do Estado democrático de direito no Brasil. Trata-se de uma revisão narrativa ou crítica da literatura, estruturada em duas partes. A primeira está assentada em uma síntese sobre o papel do Estado na concepção e na execução de políticas educacionais e na ideia de se pensar as políticas públicas ontologicamente. Já a segunda parte alicerça-se em movimentos de reverberação, de contextualização, de generalização e de síntese do discurso do cientista político Yascha Mounk.

Discutindo sobre as Políticas Públicas que favorecem a gestão democrática universitária e que sua explicitação vai além de por si mesma, isto é, se faz necessário compreender a natureza do próprio Estado e dos processos histórico-políticos. Os autores do texto Interpretação Teórico-Política da Gestão Democrática Universitária no contexto das Políticas Neoliberais, assinalam que somente a partir da consideração dos processos sociais em que se dá a reprodução do capital e a configuração do Estado, será possível tecer considerações sobre a gestão democrática universitária. Nessa direção, analisam a gestão democrática universitária a partir de uma reflexão teórico-política das contradições do Estado capitalista como instância de dominação e poder burguês no contexto das políticas neoliberais.

Para compreender as construções dos atuais sistemas de ensino no presente é importante relembrar e estudar o passado. Assim o artigo, A Orientação dos Inspetores Escolares na formação de professores no período de 1970 a 1976: um olhar sobre São Paulo apresenta as práticas de formação de professores das escolas isoladas do município de Assis, Estado de São Paulo, no período de 1970 a 1976, conduzida pelos inspetores escolares que contavam com apoio do Serviço de Orientação Pedagógica do estado. Os inspetores tinham sob sua responsabilidade a orientação e a fiscalização na implantação de um currículo que, supunha-se, trazer ao estado melhor qualidade na educação com a erradicação da repetência 
no ensino primário e, também, no cumprimento das diretrizes impostas por um programa de desenvolvimento econômico assinado entre Brasil e Estados Unidos.

O artigo intitulado: Afrontamiento, Salud Mental y Perfeccionismo en Enseñanzas Superiores: diferencias entre Músicos y Universitarios analisa a formação dos músicos na Espanha. Os estudos universitários requerem altos níveis de exigência e compromisso que supõem uma etapa educacional obrigatória muito extensa e os estudos superiores musicais também demandam uma preparação prévia muito extensa, mas com outros níveis de exigência e compromisso, que colocam seus estudantes em situações muito diversas. Considerando diferenças e semelhanças, o estudo objetiva analisar as distintas estratégias para enfrentar o stress, o perfeccionismo, a saúde mental e a valorização do sacrifício de diferentes estudantes universitários músicos.

Na mesma direção, ao refletir sobre a formação docente, os autores do artigo LIBRAS como componente curricular obrigatório: um olhar para os cursos de Licenciatura em Química das três universidades estaduais paulistas, discorrem sobre o contexto histórico que proporcionou a inserção da Língua Brasileira de Sinais (LIBRAS) como disciplina curricular obrigatória nos cursos de Licenciatura em todo o Brasil e a forma como o Decreto $\mathrm{n}^{\mathrm{o}}$ 5.626/2005 se materializa nos cursos de Licenciatura em Química de três Universidades públicas paulista. Para tanto utilizam o método de Bereday (1972), passando pelas etapas de definição, interpretação, justaposição e comparação e apresentam como cada universidade organizou o desenvolvimento da disciplina.

A Educação Infantil, primeira etapa da educação básica, que adquiriu caráter educativo com as concepções que emergiram da Constituição Federal de 1988 é discutida no artigo Políticas de Educação Infantil - desafios a partir da Criança e suas e especificidades, ancorada na Sociologia da Infância lança luz a uma nova visão das crianças e das infâncias, percebendo-as como ativas. Os autores analisam a legislação que serve como base para a realização de políticas para a Educação Infantil, buscando perceber os conceitos de criança (s) e infância (as) ali presentes.

Voltado para o papel da escola e, principalmente, do professor no reconhecimento de capacidade elevada entre os estudantes, o artigo Contribuições da escola no reconhecimento de alunos com Altas Capacidades expõe um estudo realizado com professores da Educação Básica em relação à identificação de sinais de capacidade elevada percebidos nos alunos no ambiente escolar.

Os autores do texto Altas Capacidades y Cognición Social procuram determinar as diferenças entre estudantes altamente capazes e seus pares normativamente inteligentes, 
considerando os aspectos multidimensionais que envolvem a temática. Estes assinalam que as altas capacidades, configuradas multidimensionalmente, além de um alto QI, são o resultado tanto de um processo precoce de maturação quanto de um processo de desenvolvimento psicossocial. Portanto, um campo de estudo de especial interesse é a cognição social, um campo que engloba os processos mentais que percebem, capturam e interpretam as informações sociais do meio ambiente.

O artigo, O Ensino Médio no Brasil e na França: considerações sobre a Lei 13.415/2017 a partir de uma análise comparativa discorrem sobre a propaganda da Lei 13.415/2017 de reforma curricular do ensino médio brasileiro, baseada em modelos de países centrais - entre o sistema de ensino Brasileiro e o Francês - com enfase no ponto mais polêmico da reforma: a oferta do ensino técnico, conflitante com o currículo formativo para o acesso ao ensino superior.

No artigo, Implication of social isolation on mental health during the Covid-19 pandemic: a look at its religious and spiritual coping, os autores discorrem sobre o quanto o surto de COVID-19 no s países asiátivos afetou a vida psicológicae social das pessoas, por intermédio de estudos bibliográficos analisam diferentes estudos publicados sobre a temática.

Por fim, destacamos que esse dossiê apresenta estudos tanto voltados para a Educação Comparada, quanto para outras perspectivas. No entanto, de uma forma ou de outra, buscam estabelecer relações comparativas para desenvolver suas análises. No que diz respeito, especificamente aos estudos comparativos, compreendemos que o mesmo vem ganhando espaço na pesquisa educacional. Dessa forma julgamos oportuna a organização deste número especial, concordando com o apontamento de Barroso (2011) "Nunca, como hoje, utilizou-se tanto a comparação em educação, em diferentes contextos e com diferentes propósitos, e nunca, como hoje, a educação comparada, enquanto disciplina e campo de estudo, interrogouse tanto sobre sua identidade e seu futuro" (BARROSO, 2010, p. 513).

Em fase de conclusão, não podemos deixar de sinalizar outro elemento importante, que mesmo não aparecendo nas discussões de forma específica, entra em jogo, principalmente quando discutimos o processo de globalização: a pandemia de 2020 com o Covid-19 e todas as mudanças decorrentes em relação ao impacto do fechamento das escolas e das universidades trouxeram diversas discussões no campo da comparação, que impulsionaram várias ações, tais como a da Coalizão Global de Educação lançada pela UNESCO (2020), que elaborou um documento propondo estratégias e buscando compartilhar com os países as medidas e as melhores práticas para responder aos desafios imediatos do fechamento e da reabertura das escolas. 
Assim, desejamos que este dossiê possa contribuir tanto para os estudos voltados para a Educação Comparada, quanto para fornecer referências teóricas e metodológicas que auxiliem a compreender a forma pela qual esse campo vem se delineando, bem como introduzindo o leitor na temática.

\section{REFERÊNCIAS}

BARROSO, J. Educação comparada: rotas de além-mar. Donaldo Bello de Souza, Silvia Alicia Martínez (Org.). São Paulo: Xamã, 2010.

BEREDAY, G. Z. F. Método comparado de educação. São Paulo: José de Sá Porto, 1972.

BONITATIBUS, S. G. Educação comparada: conceito, evolução, métodos. São Paulo: Edusp, 1989.

BRAY, M.; ADAMSON, B.; MASON, M. Pesquisa em educação comparada: abordagens e métodos. Brasília, DF: Liber Livro, 2015.

BRAY, M.; THOMAS, M. Levels of comparison in educational studies: different insights from different literatures and the value of multilevel analyses. Harvard Educational Review, v. 65, n. 3 , p. $472-490,1995$.

CARVALHO, E. J. Estudos comparados em educação: novos enfoques teóricometodológicos. Acta Scientiarum Education, v. 36, n. 1, p. 129-141, 2014.

COOK, B. J.; HITE, S. J.; EPSTEIN, E. H. Discerning trends, contours, and boundaries in comparative education: A survey of comparativists and their literature. Comparative Education Review, v. 48, n. 2, p. 123-149, 2004.

FERREIRA, A. G. O sentido da Educação Comparada: uma compreensão sobre a construção de uma identidade. Educação, Porto Alegre, v. 31, n. 02, p. 124-138, maio/ago. 2009.

FRANCO, M. C. Quando nós somos o outro: questões teórico-metodológicas sobre os estudos comparados. Educação \& Sociedade, ano XXI, n. 72, p.197-230, 2000.

LOURENÇO FILHO, M. B. Educação comparada. 3. ed. Brasília, DF: INEP/MEC, 2004.

MITTER, W. Educação comparada na Europa. In: COWEN, R.; KAZAMIAS, A. M.;

ULTERHALTER, E. Educação comparada: panorama internacional e perspectivas. Brasília, DF: UNESCO/CAPES, 2012. v. 1.

NÓVOA, A. Modelos de análise em educação comparada: o campo e o mapa. In: SOUZA, D. B.; MARTÍNEZ, S. A. (org.). Educação comparada: rotas além mar. São Paulo: Xamã, 2010. p. 23-63.

UNESCO. COVID-19: como a Coalizão Global de Educação da UNESCO está lidando com a maior interrupção da aprendizagem da história. 2020. Disponível em: 
https://pt.unesco.org/news/covid-19-como-coalizao-global-educacao-da-unesco-esta-lidandocom-maior-interrupcao-da. Acesso em: 10 jun. 2021.

\section{Como referenciar este artigo}

SANTOS, R.; SALOTTI, L. S. R. Editorial - Educação comparada: desafios e possibilidades no campo metodológico. Revista on line de Política e Gestão Educacional, Araraquara, v. 25, n. esp. 4, p. 1874-1880, dez. 2021. e-ISSN:1519-9029. DOI: https://doi.org/10.22633/rpge.v25iesp.4.15929

Submetido em: $20 / 08 / 2021$

Revisões requeridas em: 12/10/2021

Aprovado em: $15 / 11 / 2021$

Publicado em: 08/12/2021 